\title{
Penggunaan Jaringan Syaraf Tiruan dan Wavelet Pada Citra Electrocardiagram 12 Lead
}

\section{The Use of Artificial Neural Networks and Wavelets in 12-Lead Electrocardiagram Images \\ Darwan}

IAIN Syekh Nurjati Cirebon, Indonesia

\begin{tabular}{l}
\hline Article Info \\
\hline Article history: \\
Received, 10 Februari 2021 \\
Revised, 28 April 2021 \\
Accepted, 5 Mei 2021 \\
\\
\hline Kata Kunci: \\
Electrocardiogram \\
Sym4 \\
Bacpropagation \\
k-fold cross validation \\
Syaraf Tiruan \\
\hline \hline
\end{tabular}

Keywords:

Electrocardiogram

Sym4

Bacpropagation

$k$-fold cross validation

Artificial neural network

\begin{abstract}
ABSTRAK
Jantung sangat penting dalam sistem organ tubuh manusia. Apabila terjadi kesalahan pada fungsi jantung akibatnya sangat fatal. Oleh karenanya sangatlah penting menjaga kondisi jantung agar tetap sehat. Penelitian ini mencoba menawarkan untuk meneliti terkait kelainan jantung dengan menggunakan citra Electrocardigram (EKG) 12 lead. Data EKG yang digunakan berupa citra. Tujuan penelitian ini untuk memperoleh model yang tepat dalam mengidentifikasi kelainan jantung dengan menggunakan wavelet. Tahapan penelitian terdiri dari pre-processing, ekstraksi ciri dan klasifikasi. Tahap pre-processing menggunakan metode segmentasi (merubah data citra dari grayscale ke biner), morfologi (metode dilasi dan metode erosi) dan transformasi ke sinyal. Tahap ektraksi ciri menggunakan metode dekomposisi transformasi wavelet dengan tingkatan tiga level, dimana mother wavelet yang digunakan berupa symlet orde 4 (Sym4). Tahap klasifikasi menggunakan jaringan syaraf tiruan dengan metode backpropagation. Adapun metode validasi dan evaluasi menggunakan $k$-fold cross validation dan confusion matrix. Penggunaan metode $k$-fold cross validation, dimana $k=5$ dengan pembagian data training $80 \%$ dan testing $20 \%$. Hasil yang diperoleh dari keseluruhan sistem dimana tingkat akurasi sebesar $92,94 \%$, sensitifitas sebesar $90 \%$ dan spesifisitas sebesar $94,55 \%$.
\end{abstract}

\section{ABSTRACT}

The heart is very important in the organ system of the human body. If there is an error in heart function the result is very fatal. Therefore, it is very important to maintain a healthy heart condition. The study tried to offer to examine related heart abnormalities using an ECG image of 12 leads. ECG data used in the form of images. The purpose of this study is to obtain the right model in identifying heart abnormalities by using wavelets. The research phase consists of pre-processing, character extraction and classification. The preprocessing stage uses segmentation methods (converting image data from grayscale to binary), morphology (dilation methods and erosion methods) and transformation to signals. The characteristic extraction stage uses the wavelet transformation decomposition method with three levels, where the mother wavelet used is a 4th order symlet (Sym4). The classification stage uses artificial neural networks with backpropagation method. The validation and evaluation method uses $k$-fold cross validation and confusion matrix. The use of $k$-fold cross validation method, where $k=5$ with $80 \%$ training data sharing and $20 \%$ testing. The results were obtained from the entire system where the accuracy rate was $92.94 \%$, the sensitivity was $90 \%$ and the specificity was $94.55 \%$.

This is an open access article under the CC BY-SAlicense.

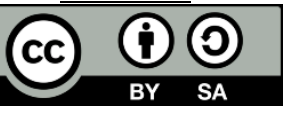

Penulis Korespondensi:

Darwan,

Jurusan Tadris Matematika,

IAIN Syekh Nurjati Cirebon,

Email: darwan@syekhnurjati.ac.id 


\section{PENDAHULUAN}

Jantung merupakan salah satu bagian dari organ tubuh manusia yang sangat penting. Kelainan jantung masih menempati urutan teratas kematian di dunia. Penyakit jantung merupakan penyebab utama kematian di seluruh dunia [1]. Penyakit jantung ini menjadi penyebab sepertiga dari seluruh kematian yang ada di dunia pada tahun 2019, serta jumlah kematiannya yang terus meningkat. Sedangkan sebagian besar kematian akibat penyakit jantung dikaitkan dengan kelainan jantung iskemia pada tahun 2019. America Heart Association menyebutkan bahwa hampir setiap satu dari tiga orang yang meninggal disebabkan oleh penyakit kardiovaskular. Oleh sebab itu, kita diharapkan menjaga kondisi tubuh terutama jantung agar tetap sehat.

Pendekteksian kelainan jantung secara dini dapat dilakukan dengan melakukan pengecekan kondisi jantung dengan alat bantu seperti: elektrokardiogram (EKG), pemeriksaan darah, scanning jantung nuklir, kateterisasi jantung, uji latih jantung, ekokardiografi dan angiografi koroner [2]. Alat yang sering digunakan di beberapa rumah sakit dan klinik kesehatan untuk mengecek kelainan jantung yaitu elektrokardiogram (Gambar 1). Pendeteksian kelainan jantung menggunakan EKG cara kerjanya sangat sederhana. Alat EKG yang terdiri 12 lead dipasang di beberapa bagian tubuh, selanjutnya direkam dan hasilnya dikeluarkan dalam bentuk kertas grafik EKG. Dari kertas grafik EKG tersebut dapat dianalisis apakah pasien jantung dalam kondisi normal atau ada kelainan. Klasifikasi yang tepat dari penyakit ini memungkinkan untuk menerapkan pengobatan yang lebih terfokus [1].

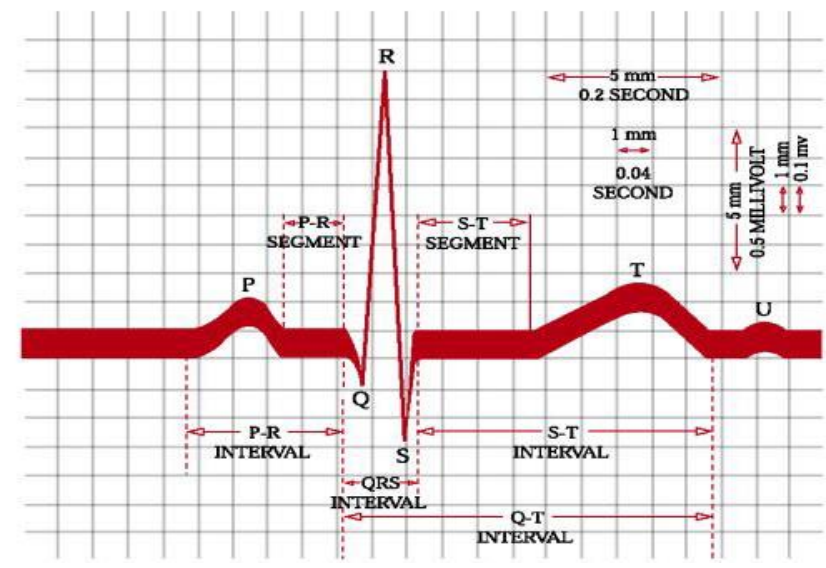

Gambar 1. Contoh EKG Normal [3]

Beberapa dekade ini pemrosesan sinyal digital dalam dunia medis telah menjadi hal penting untuk membantu dokter dalam mengambil keputusan pada permasalahan medis [4]. Beban faktor risiko kematian seperti yang dijelaskan diatas telah memotivasi para peneliti untuk menyumbangkan pola, model dan algoritma [5]. Analisis terhadap sinyal EKG merupakan salah satu solusi yang dapat membantu untuk mendeteksi dan mengelompokkan sinyal serta bentuk gelombang yang berbeda[6]. Pemrosesan sinyal EKG dan klasifikasi fitur berdasarkan pembelajaran mesin memainkan peran penting dalam mendukung sistem yang disebutkan di atas [5]. Berdasarkan hal tersebut analisis berbasis komputer sangat berguna dalam diagnostik [7]. Sistem komputer dalam hal ini dapat membantu mengidentifikasi kondisi kelistrikan jantung [8]. Penelitian ini pada dasarnya akan melakukan analsis sinyal EKG yang diperoleh dari keluaaran alat EKG yang berupa print-out. Hasil print-out di scan dan ditransformasi ke bentuk spatial. Ektraksi ciri menggunakan wavelet dan klasifikasi menggunakan backpropagation.

\section{METODE PENELITIAN}

Beberapa penelitian terkait dengan EKG diantaranya [4], melakukan penelitian untuk menganalisis dan mengklasifikasi sinyal EKG yang diperoleh dari Physionet pada sadapan II, berbasis transformasi wavelet dan jaringan syaraf tiruan backpropagation dengan rata-rata akurasi $87,42 \%$. Penelitiann terkait sinyal EKG yang dimasukkan ke sistem diagnosis otomatis, dengan menerapkan wavelet berdasarkan fungsi atom untuk menghilangkan noise dan baseline wander. Sinyal EKG dibagi menjadi 1, 2, 5, dan 10 detik yang diinputkan ke klasifikasi, dan hasilnya dapat membedakan 11 jenis sinyal EKG dengan akurasi $98,9 \%$ [1].

Penelitian terkait EKG pernah dilakukan dengan mengambil citra EKG 12 Lead. Tahap pre-processing yang digunakan yaitu segmentasi (grayscale ke biner), morfologi (dilasi dan erosi), dan transformasi citra ke bentuk spatial. Ektraksi ciri untuk mencari puncak P, Q, R, S, T, Heart Rate dan ST-Deviasi. Hasil yang diperoleh untuk puncak-puncak EKG yang di dapat telah mewakili secara medis [9].

Selanjutnya [10], memperkenalkan metode untuk deteksi AF (fibrilasi atrium) otomatis menggunakan sinyal EKG dua arah dari database MIT-BIH dengan menggunakan transformasi paket wavelet (WPT) dan fungsi korelasi. Ciri statistik merupakan input klasifikasi jaringan saraf tiruan. Evaluasi kinerja menggunakan validasi silang 10 kali dan hasilnya membuktikan bahwa strategi yang diusulkan menghasilkan kinerja yang superior. Berikutnya [11], penelitian delapan set aturan pemilihan nilai ambang yang berbeda diimplementasikan dan dievaluasi pada database aritmia MIT-BIH. Hasilnya menunjukkan kinerja yang 
lebih tinggi dalam hal SNR, MSE dan PRD yang lebih rendah. Penelitian ke depan [11], menyarankan agar dikembangkan untuk memilih ciri yang optimal dari kumpulan fitur yang selanjutnya digunakan untuk membantu dokter dalam mendeteksi kelainan jantung.

Berdasarkan saran tersebut [11], penelitian ini mencoba untuk menggunakan pendekatan baru terkait kelainan jantung dengan menggunakan citra EKG 12 lead. Citra EKG di scan pada tahap pre-processing dan di transformasi ke dalam sinyal sesuai dengan metode yang dilakukan [9], kemudian hasilnya sebagai masukkan ekstraksi ciri. Ekstraksi ciri menggunakan dekomposisi transformasi wavelet, dengan mother wavelet symlet orde empat (Sym4). Hasil ekstraksi ciri menjadi inputan pada proses klasifikasi menggunakan jaringan syaraf tiruan dengan metode backpropagation untuk membedakan data EKG normal, iskemia dan aritmia. Hasil akhir dari penelitian ini berupa tingkat akurasi, sensitifitas, dan spesifisitas.

Metode yang diusulkan peneliti terdiri dari tiga tahap, diantaranya pre-processing, ektraksi ciri dan klasifikasi. Sedangkan untuk melihat validasi dan evaluasi menggunakan metode $k$-fold cross validation dan confusion matrix untuk memperoleh tingkat akurasi, sensitifitas, dan spesifisitas. Metode $k$-fold cross validation dengan $K=5$, dimana pembagian masing-masing $K$ dengan komposisi $80 \%$ data Training dan $20 \%$ data Testing.

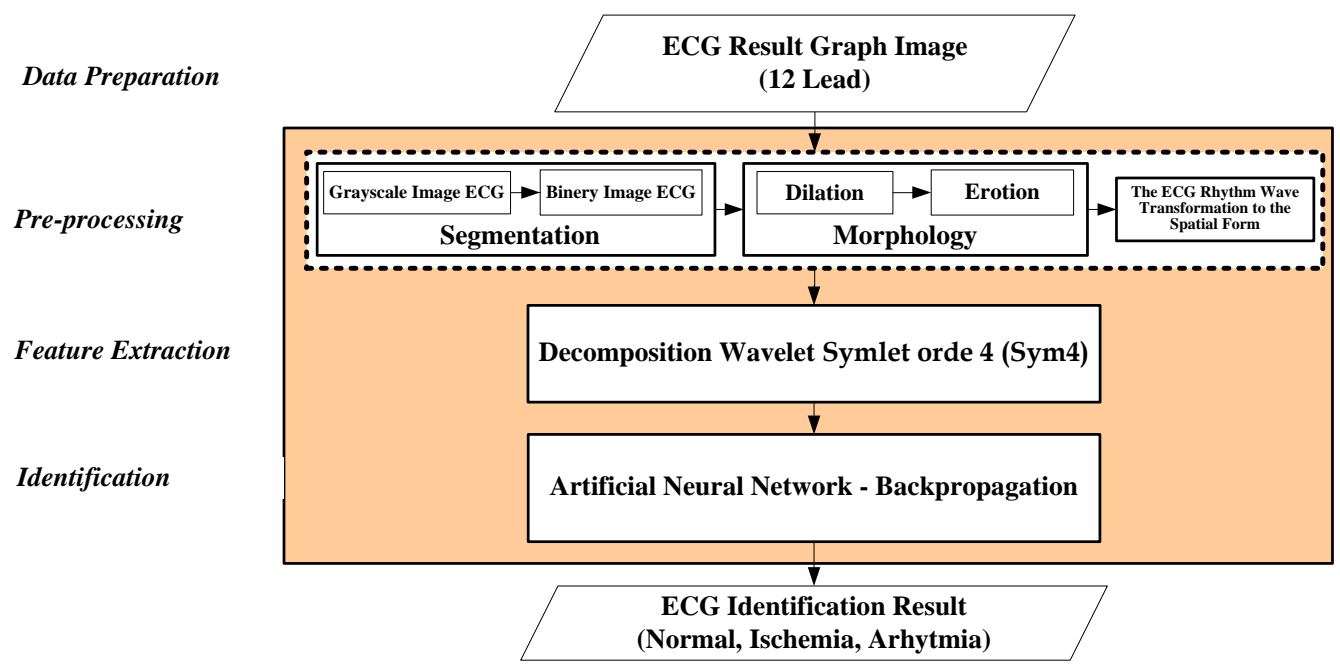

Gambar 2. Model yang diusulkan

\subsection{Dataset}

Data EKG 12 lead dalam penelitian ini diambil dari RSUD Sardjito Yogyakarta dengan jumlah total 30 data pasien, dengan data EKG normal, kelainan Iskemia dan Aritmia masing-masing sebanyak 10 data EKG. Satu pasien dalam print-out EKG ada 12 lead (I, II, III, aVR, aVL, aVF, V1, V2, V3, V4, V5 dan V6), sehingga akan terdapat 12 image per EKG. Komposisi masingmasing kondisi jantung dapat dilihat pada Tabel 1.

Tabel 1. Sebaran Data Pasien

\begin{tabular}{ccccc}
\hline No. & Kondisi & Pasien & Lead & Jumlah Citra \\
\hline 1. & Normal & 10 & 12 & 120 \\
2. & Iskemia & 10 & 12 & 120 \\
3. & Aritmia & 10 & 12 & 120 \\
\hline
\end{tabular}

Dari tabel 1, kita dapat mengolah data EKG total sebanyak 360 data citra. Gambar 3 merupakan salah satu contoh dari satu lead pada EKG.

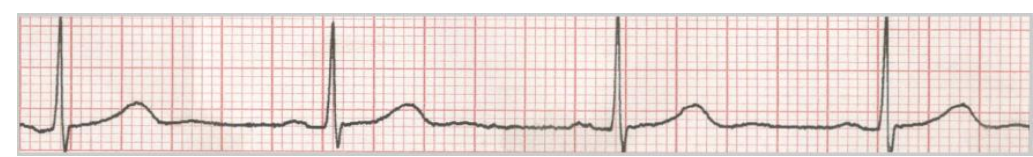

Gambar 3. Contoh Citra EKG Pada Lead V6

\subsection{Pre-Processing}

Tahap pre-processing sama dengan yang dilakukan oleh [9]. Rangkaian tahap pre-processing terdiri dari segmentasi, morfologi dan transformasi dari citra EKG ke bentuk spatial. Segmentasi dalam penelitian ini terdiri dari proses yaitu merubah 
citra warna ke bentuk grayscale dan merubah grayscale ke citra biner. Citra biner (binary image) merupakan citra digital yang hanya memiliki 2 kemungkinan warna, yaitu hitam dan putih.

Morfologi dalam penelitian ini digunakan untuk mengatasi objek yang terputus menjadi tersambung kembali (mendekati bentuk aslinya). Untuk memperbaiki bentuk grafik EKG, dilakukan operasi morfologi yaitu dilasi dan erosi.

\subsection{Feature Extraction}

Tahap kedua dalam penelitian ini yaitu melakukan ekstraksi ciri menggunakan wavelet. Wavelet merupakan suatu himpunan fungsi yang dihasilkan oleh suatu fungsi tunggal $\psi$ dengan proses dilasi dan translasi [12].

$$
\emptyset_{a, b}(\mathrm{t})=|a|^{-1 / 2} \varnothing\left(\frac{t-b}{a}\right)
$$

Dengan $\varnothing(t)$ sebagai fungsi wavelet induk (mother wavelet). a merupakan parameter dilasi $a$, dan $B$ adalah parameter translasi. Penelitian ini menggunakan transformasi wavelet dekomposisi, yaitu suatu metode pengolahan sinyal dimana sebuah sinyal dipecah menjadi beberapa bagian. Transformasi wavelet dekomposisi sebagai penggambaran sebuah skala waktu sinyal digital didapatkan dengan menggunakan teknik filterisasi digital. Sebuah sinyal harus dilewatkan dalam dua filterisasi yaitu highpass filter dan lowpass filter agar frekuensi dari sinyal tersebut dapat dianalisis. Proses dekomposisi ini dapat melalui satu atau lebih tingkatan. Contoh dekomposisi sinyal satu tingkat pada Gambar 4.

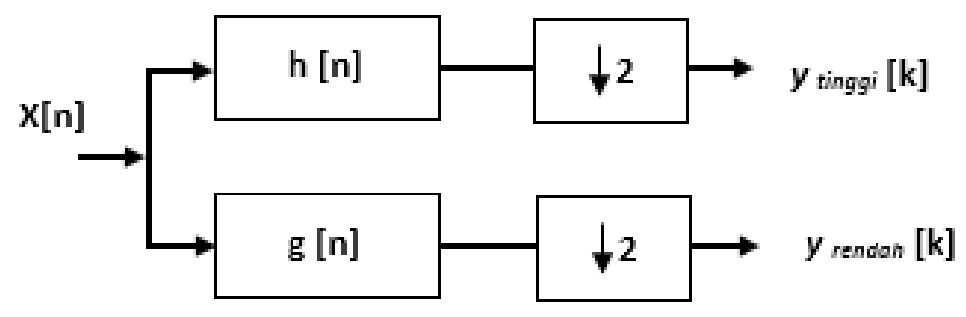

Gambar 4. Contoh Dekomposisi Sinyal

Pada gambar 4, hasil dari highpass filter, ytinggi [k] disebut sebagai sinyal detil (detail signal) dan hasil dari lowpass filter, yrendah [k] disebut sebagai sinyal aproksimasi (approximation signal), $\mathrm{x}$ [n] merupakan sinyal asal. Dekomposisi sinyal satu tingkat ditulis dengan ekspresi matematika pada persamaan 2 dan 3.

$$
\begin{aligned}
& y_{\text {tinggi }}[\mathrm{k}]=\sum_{n}[n] h[2 k-n] \\
& y_{\text {rendah }}[\mathrm{k}]=\sum_{n}[n] g[2 k-n]
\end{aligned}
$$

ytinggi $[\mathrm{k}]$ dan yrendah $[\mathrm{k}]$ adalah hasil dari highpass filter dan lowpass filter, $\mathrm{h}[\mathrm{n}]$ adalah highpass filter dan g[n] adalah lowpass filter, $\mathrm{n}$ dan $\mathrm{k}$ adalah variabel integer. Sinyal arus dalam ini berfungsi sebagai sinyal utama atau mother wavelet. Ketika proses dekomposisi dijalankan maka sinyal approximation coefficient akan menjadi mother wavelet dan terdekomposisi berdasarkan highpass dan lowpass filter, dan seterusnya sesuai dengan level yang kita inginkan. Pada dekomposisi wavelet sinyal dibagi menjadi komponen aproksimasi dan detail. Komponen aproksimasi kemudian dibagi lagi menjadi komponen apkroksimasi dan detail, begitu seterusnya sampai level yang diinginkan.

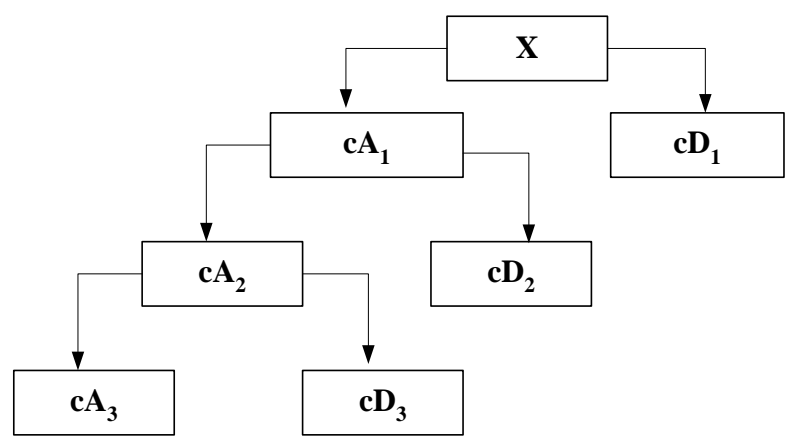

Gambar 5. Dekomposisi Wavelet

Secara matematis dekomposisi wavelet level 3 dapat di tulis seperti persamaan 4 .

$$
\begin{aligned}
\mathrm{X} & =\mathrm{cA}_{1}+\mathrm{cD}_{1} \\
& =\mathrm{cA}_{2}+\mathrm{cD}_{2}+\mathrm{cD}_{1} \\
& =\mathrm{cA}_{3}+\mathrm{cD}_{3}+\mathrm{cD}_{2}+\mathrm{cD}_{1}
\end{aligned}
$$


Dimana X dekomposisi suatu sinyal, dengan A dinamakan koefisien aproksimasi tingkat ke $\boldsymbol{i}$, dan D dinamakan koefisien detail pada tingkat $\boldsymbol{i}$. Penelitian ini menggunakan Transformasi Wavelet Dekomposisi. Mother wavelet yang digunakan yaitu symlet dengan orde 4 (Sym4) dengan hasil akhir memperoleh nilai koefisien aproksimasi koefisien detail masing-masing.

\subsection{Identification}

Identifikasi dalam penelitian ini menggunakan jaringan syaraf tiruan dengan metode backpropagation. Jaringan saraf mengikuti contoh otak manusia, serta model jaringan saraf juga sering disebut model koneksionis [13]. Ketertarikan pada jaringan syaraf tiruan karena dapat membantu dalam membangun sistem komputer yang lebih baik [14]. Jaringan syaraf tiruan telah banyak diterapkan untuk berbagai keperluan, seperti klasifikasi, pengenalan pola, prediksi dan peramalan, kontrol proses, pengoptimalan, serta pengambilan keputusan [15]. Ciri dari jaringan syaraf dicirikan oleh arsitektur jaringan, karakteristik node, dan aturan pembelajaran [13]. Jaringan syaraf tiruan dalam menyelesaikan suatu masalah melalui proses pembelajaran yang di berikan dari contoh pelatihan [16]. Algoritma backpropagatin digunakan untuk pelatihan, mudah dan sederhana, serta dapat bekerja dengan baik, bahkan dengan data yang kompleks [17]. Topologi backpropagation melibatkan tiga lapisan: lapisan masukan, lapisan tersembunyi, dan lapisan keluaran [18].

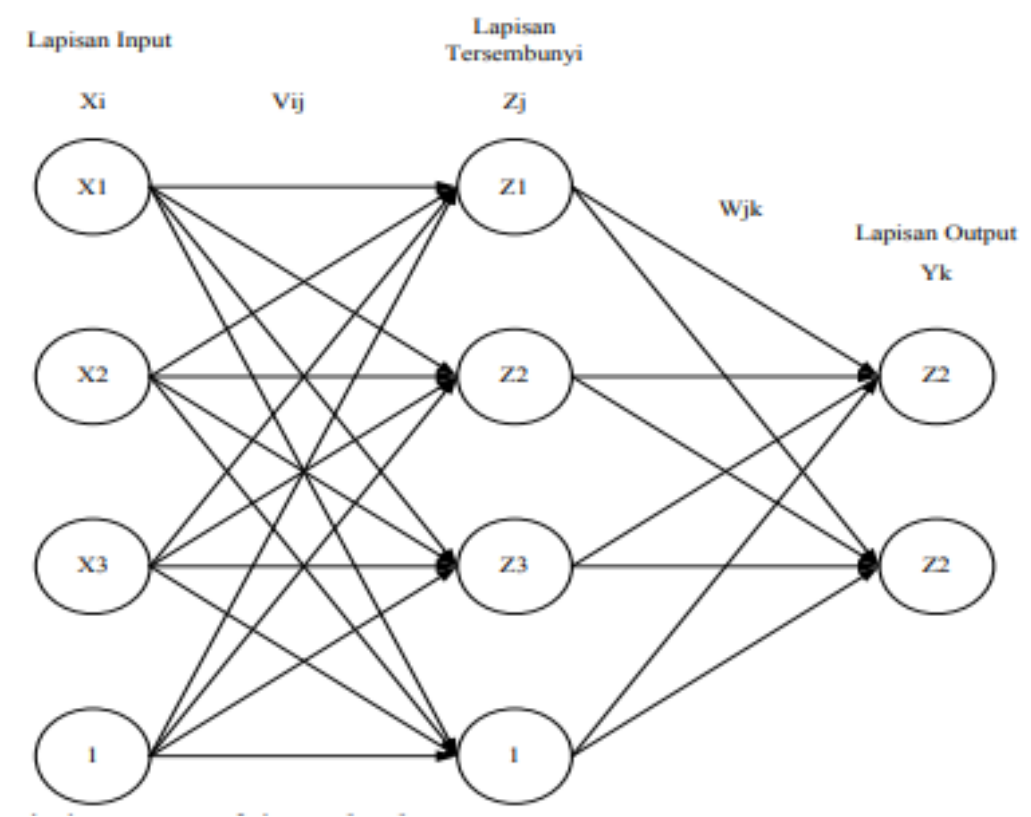

Gambar 6. Contoh Arsitektur Backpropagation [19]

Pada gambar 6 lapisan-lapisan pada jaringan syaraf tiruan terdiri dari tiga lapisan penyusun:

1. Lapisan Input (Input Layer)

Gambar 6 jaringan terdiri dari beberapa unit (neuron) pada lapisan input yaitu $\mathrm{x}_{\mathrm{i}}$.

2. Lapisan Tersembunyi (Hidden Layer)

Lapisan penyusun yang kedua yaitu lapisan tersembunyi yang terdiri dari tiga neuron, yaitu $\mathrm{z}_{\mathrm{j}}$.

3. Lapisan Output (Output Layer)

Lapisan terakhir yaitu lapisan output, dimana pada gambar 6 hanya terdiri diri dari beberapa neuron $\left(\mathrm{Y}_{\mathrm{k}}\right)$

Backpropagation telah banyak diterapkan untuk berbagai aplikasi penelitian. Penelitian-penelitian yang menggunakan backpropagation seperti identifikasi tulisan jawa [20]. Selanjutnya [21] sebagai pengenalan pola untuk menggali potensi mahasiswa baru. Perkembangan terakhir banyak digunakan untuk berbagai studi kasus disiplin ilmu salah satunya yaitu terkait dengan kesehatan.

\subsection{K-Fold Cross Validation}

Metode terakhir yang digunakan untuk mencari tingkat validitas dari sebuah sistem. Metode yang digunakan dalam penelitian ini yaitu $k$-fold cross validation. Dalam $k$-fold cross validation, di mana $k \geq 2$ adalah bilangan bulat, dataset yang digunakan akan dipartisi menjadi $k$ bagian [22]. Secara umum $k$-fold cross validation semua data yang digunakan akan diperlakukan secara sama, yaitu sebagai data training dan testing. Misal data yang digunakan akan kita bagi menjadi 3-fold cross validation, berarti kumpulan data tersebut akan dibagi menjadi tiga bagian. Pada percobaan pertama diperlakukan duapertiga data pertama akan diperlakukan sebagai data training dan sepertiga lainnya diperlakukan sebagai data testing, dan ini akan terus di coba sesuai dengan pembagian $k$-nya. 
Tabel 2. Ilustrasi 3-Fold Cross Validation

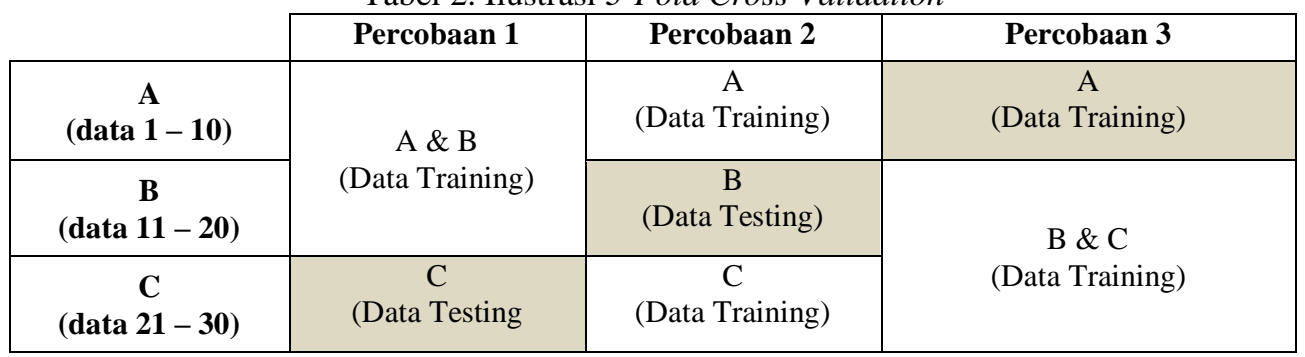

Dari $k$-fold cross validation kita dapat mencari tingkat akurasi, sensitifitas dan spesifisitas dengan menggunakan confusion matrix. Confusion matrik merupakan salah satu metode yang berguna untuk menganalisis seberapa baik kelas yang kita gunakan dapat mengenali data dari kelas yang berbeda [23].

Tabel 3. Model confusion matrix

\begin{tabular}{ccc}
\hline \multirow{2}{*}{ Klasifikasi Yang Benar } & \multicolumn{2}{c}{ Diklasifikasikan Sebagai } \\
\cline { 2 - 3 } & + & - \\
\hline+ & TP & FN \\
- & FP & TN \\
\hline
\end{tabular}

(7) $[23]$ :

Akurasi diperoleh dengan persamaan (5), sensitifitas diperoleh dengan persamaan (6), dan spesifisitas dengan persamaan

$$
\begin{aligned}
& \text { Akurasi }=\frac{T P+T N}{T P+T N+F P+F N} \times 100 \% \\
& \text { Sensitifitas }=\frac{T P}{T P+F N} \times 100 \% \\
& \text { Spesifisitas }=\frac{T N}{T N+F P} \times 100 \%
\end{aligned}
$$

Dimana:

$$
\begin{aligned}
& \mathrm{TP}=\text { True Positive }, \\
& \mathrm{TN}=\text { True Negative }, \\
& \mathrm{FP}=\text { False Positive }, \text { dan } \\
& \mathrm{FN}=\text { False Negative } .
\end{aligned}
$$

\section{HASIL DAN ANALISIS}

Berdasarkan urutan pengolahan data dapat di sajikan hasil sesuai tahapannya yaitu pre-processing, ektraksi ciri, identifikasi dan akurasi. Analisis dalam penelitian menggunakan MATLAB Versi 7.0.4. Setiap tahapan proses yang dikerjakan (Gambar 2) semuanya dianalisis menggunakan tools tersebut.

\subsection{Pre-processing}

Pada tahap pre-processing mengikuti tahapan yang dilakukan oleh [9] (Tabel 4). Pre-processing yang dilakukan diantaranya pembacaan citra EKG 12 lead, segmentasi (grayscale ke biner), morfologi (dilasi dan erosi), dan transformasi citra ke bentuk spatial. 
Tabel 4. Langkah-langkah Tahap Pre-processing [9]

Citra EKG

Grayscale

Biner

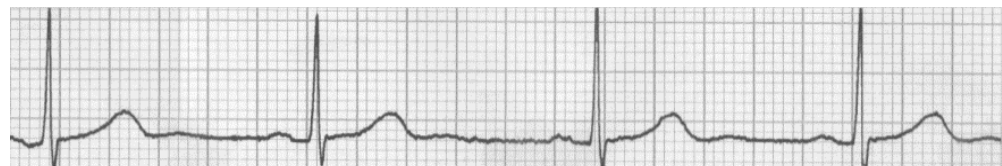

Dilasi

Erosi

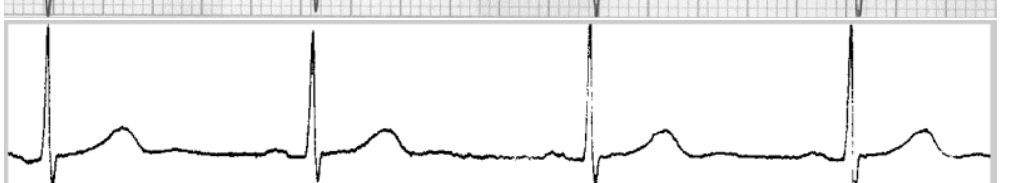

Grafik

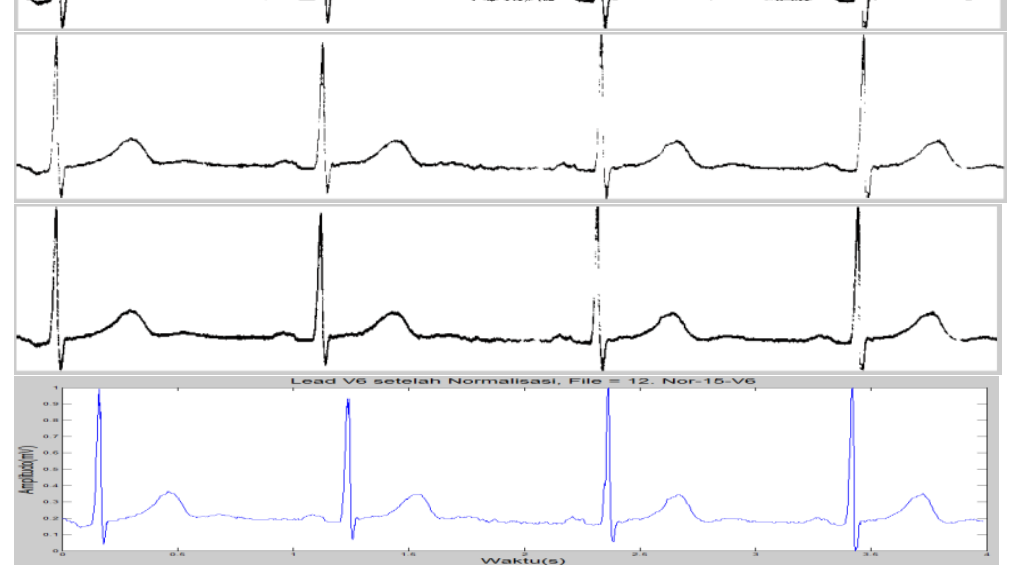

Hasil dari tahap pre-processing akan menjadi bahan inputan untuk ektraksi ciri.

\subsection{Ekstraksi Ciri}

Ekstraksi ciri penelitian ini menggunakan metode wavelet, dengan mother wavelet symlet orde 4 (Sym4). Metode yang digunakan yaitu transformasi wavelet dekomposisi level 3. Inputan dari citra EKG 12 lead akan di ekstrak untuk memperoleh data aproksimasi dan detail energi pada level 3 tersebut. Sehingga data EKG yang keluar dari masing-masing lead yaitu koefisien aproksimasi, detail 1, detail 2 dan detail 3. Hasil ekstraksi ciri dari tabel 2 dengan menggunakan persamaan (4) pada lead V6 setelah di normalkan dapat ditulis untuk masing-masing koefisien aproksimasi dan detailnya sebagai berikut:

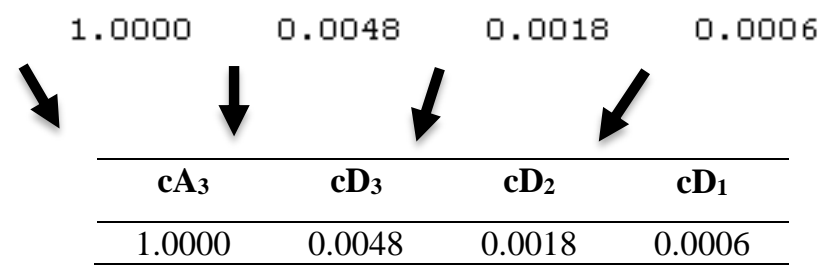

Gambar 7. Ilustrasi Koefisien Aproksimasi dan Detail pada lead V6

Dari satu lead (Tabel 4) kita dapat memperoleh 4 buah data sehingga dari 12 lead (satu pasien) kita dapat memperoleh 48 data. Semua data pasien yang di pakai di ekstraksi dengan menggunakan cara yang sama. Hasil dari tahap ekstraksi ciri menjadi masukan untuk jaringan syaraf tiruan.

\subsection{Identifikasi}

Tahap ketiga kita menggunakan jaringan syaraf tiruan backpropagation dengan menginputkan data hasil ekstraksi ciri untuk inputan ke dalam neuronnya. Data input yang dimasukkan sebanyak 48 data dan output berupa target jaringan berupa salah satu 
dari tiga target (Tabel 5). Untuk data yang dimasukkan ke dalam jaringan telah diklasifikasi sebagai data normal, iskemia dan aritmia dengan masing-masing data yaitu 10 data pasien, sehingga total data pelatihan sebanyak 30 data pasien yang telah di klasifikasi.

Tabel 5. Output dan target jaringan syaraf tiruan

\begin{tabular}{lc}
\hline \multicolumn{1}{c}{ Output Jaringan } & Target Jaringan \\
\hline Normal & 1 \\
Iskemia & 2 \\
Aritmia & 3 \\
\hline
\end{tabular}

Setelah semua data dan target ditentukan kita dapat membangun pelatihan jaringan sesuai yang telah kita setting. Hasil dari pelatihan jaringan gambar 8 .

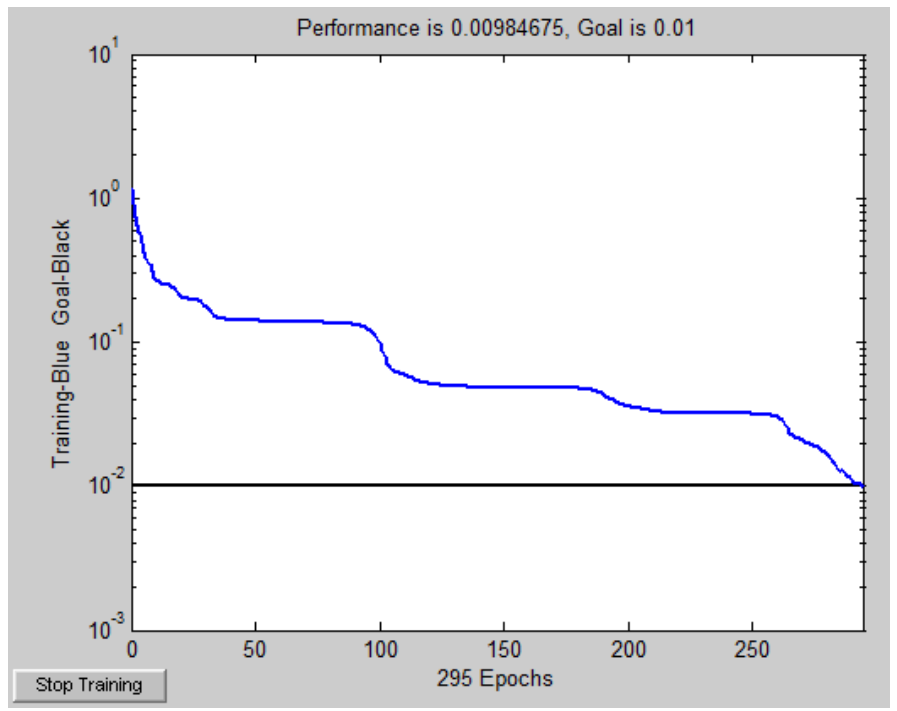

Gambar 8. Pelatihan Jaringan

Hasil testing Data Training pelatihan dapat dilihat pada gambar 9.

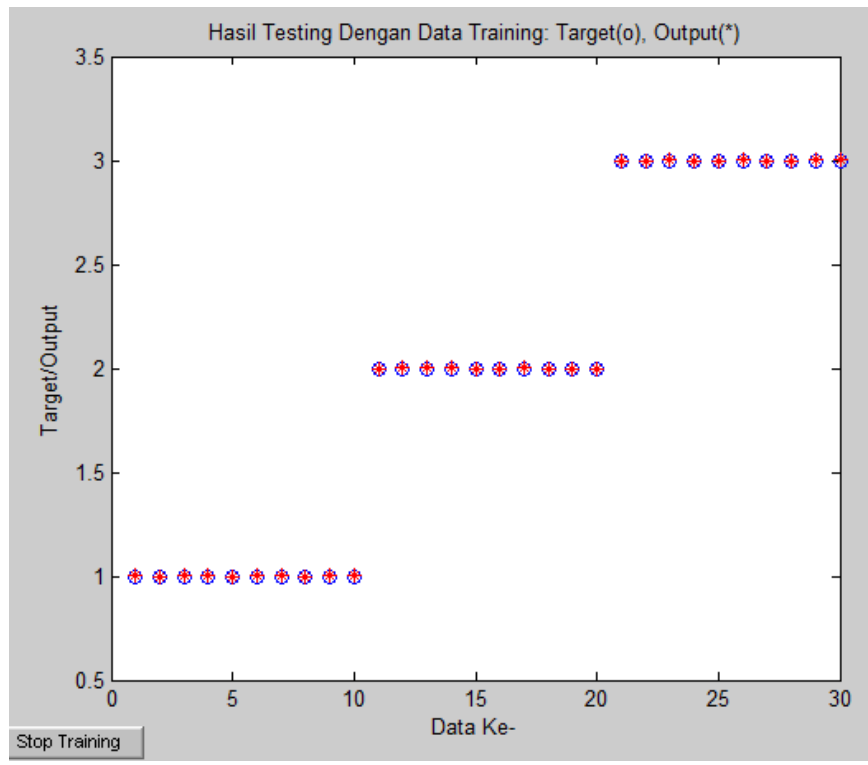

Gambar 9. Hasil Pengujian dan Pelatihan

Hasil pelatihan kita dapat di analisis dan evaluasi dengan melihat data pelatihan dan target gambar 10 dan gambar 11 . 


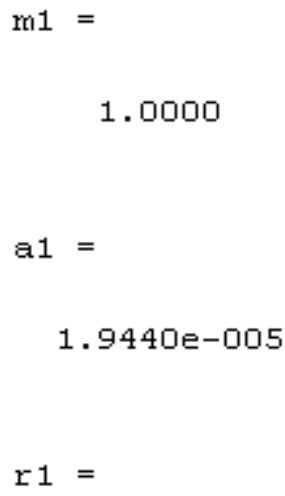

Gambar 10. Screenshot Hasil Analisis Data Pelatihan dan Target

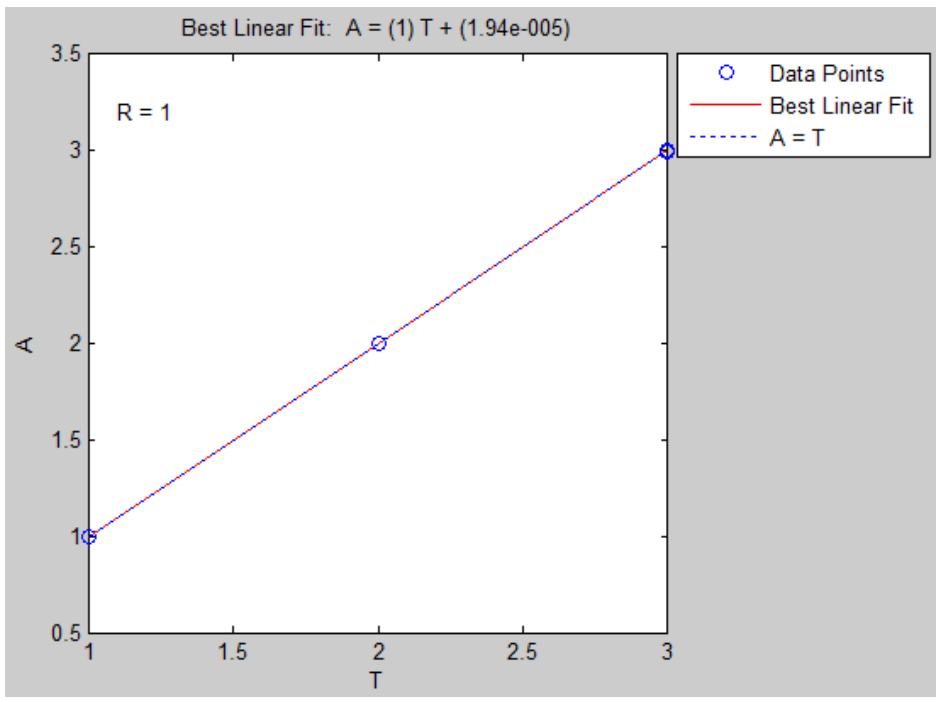

Gambar 11. Hasil Evaluasi antara Data Pelatihan dan Target

Setelah dilakukan pelatihan selanjutnya dilakukan pengujian dengan memasukkan data pengujian (testing). Data testing digunakan untuk menguji apakah sistem yang telah dilatih dapat mengenali data baru atau tidak. Hasil pengujian ketika dimasukkan data baru dengan data normal, sistem mengenali sebagai data normal (Gambar 12).

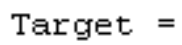

Normal

Gambar 12. Contoh Screenshot Hasil Pengujian

\subsection{Akurasi}

Sistem yang telah dilatih (training) dan diuji (testing) berjalan dengan baik kita perlu menguji untuk tingkat validasinya. Untuk validasi disini menggunakan $k$-fold cross validation, yaitu setiap data yang digunakan akan memperoleh perlakuan yang sama sebagai data training dan testing. Penelitian ini menggunakan $k$-fold dengan $\mathrm{K}=5$, dan pembagian masing-masing data training dan testing yaitu $80 \%$ data training dan 20\% data testing. Tabel 6 merupakan hasil evaluasi untuk memperoleh nilai akurasi, sensitifitas dan spesifisitas dengan menggunakan persamaan 5, 6 dan 7 . 
Tabel 6. Hasil Validasi Untuk Akurasi, Sensitifitas dan Spesifisitas

\begin{tabular}{|c|c|c|c|c|c|c|c|c|c|}
\hline \multicolumn{2}{|c|}{$K=1$} & \multicolumn{2}{|c|}{$K=2$} & \multicolumn{2}{|c|}{$\mathbf{K}=\mathbf{3}$} & \multicolumn{2}{|c|}{$K=4$} & \multicolumn{2}{|c|}{$K=5$} \\
\hline Kondisi & Hasil & Kondisi & Hasil & Kondisi & Hasil & Kondisi & Hasil & Kondisi & Hasil \\
\hline Normal-09 & Normal & Normal-07 & Normal & Normal-05 & Normal & Normal-03 & Normal & Normal-01 & Normal \\
\hline Normal-10 & Normal & Normal-08 & Normal & Normal-06 & Normal & Normal-04 & Normal & Normal-02 & Normal \\
\hline Iskemia-09 & Aritmia & Iskemia-07 & Iskemia & Iskemia-05 & Iskemia & Iskemia-03 & Iskemia & Iskemia-01 & Iskemia \\
\hline Iskemia-10 & Iskemia & Iskemia-08 & Iskemia & Iskemia-06 & Aritmia & Iskemia-04 & Iskemia & Iskemia-02 & Iskemia \\
\hline Aritmia-09 & Aritmia & Aritmia-07 & Aritmia & Aritmia-05 & Aritmia & Aritmia- 03 & Aritmia & Aritmia-01 & Aritmia \\
\hline Aritmia-10 & Aritmia & Aritmia- 08 & Aritmia & Aritmia-06 & Aritmia & Aritmia-04 & Normal & Aritmia-02 & Aritmia \\
\hline Akurasi (\%) & 88,24 & Akurasi (\%) & 100,00 & Akurasi (\%) & 88,24 & Akurasi (\%) & 88,24 & Akurasi (\%) & 100,00 \\
\hline Sensitifitas (\%) & 83,33 & Sensitifitas (\%) & 100,00 & Sensitifitas $(\%)$ & 83,33 & Sensitifitas (\%) & 83,33 & Sensitifitas (\%) & 100,00 \\
\hline Spesifisitas (\%) & 90,91 & Spesifisitas $(\%)$ & 100,00 & Spesifisitas (\%) & 90,91 & Spesifisitas (\%) & 90,91 & Spesifisitas (\%) & 100,00 \\
\hline
\end{tabular}

Dari tabel 6 dapat diketahui bahwa rata-rata prosentase untuk akurasi yaitu 92,94\%, sensitifitas sebesar $90 \%$ dan spesifisitas sebesar $94,55 \%$.

\section{KESIMPULAN}

Berdasarkan rangkaian penelitian citra EKG 12 lead dari awal dan ektraksi ciri dengan menggunakan metode dekomposisi transformasi wavelet level 3 pada symlet orde 4 (Sym4) diperoleh data koefisien aproksimasi dan detailnya. Data ekstraksi yang di dapat sebagai bahan inputan untuk jaringan syaraf tiruan yang menggunakan metode backpropagation. Tingkat validasi sistem yang telah diuji menggunakan $k$-fold cross validation, diperoleh tingkat akurasi sebesar 92,94\%, sensitifitas sebesar $90 \%$ dan spesifisitas sebesar 94,55\%. Berdasarkan hasil validasi tersebut dapat diambil kesimpulan bahwa model yang diusulkan dapat dijadikan bahan pertimbangan untuk membangun sistem terkait identifikasi kelainan jantung. Hasil penelitian ini masih banyak kekurangan dan mungkin jauh dari hasil ideal, sehingga pengembangan atau tindak lanjut penelitian kedepan terkait dengan EKG masih perlu ditingkatkan. Karena cakupan penelitian medis yang dibantu dengan komputer sangat luas dan perlu pendekatan yang berbeda-beda.

\section{REFERENSI}

[1] A. H. Matamoros, H. Fujita, E. E. Hernandez, H. P. Meana, and M. N. Miyatake, "ScienceDirect Recognition of ECG signals using wavelet based on atomic functions," Journal Biocybernetics and Biomedical Engineering, vol. 40, no. 2, pp. 803-814, 2020.

[2] J.-G. Yang, J.-K. Kim, U.-G. Kang, and Y. Lee, "Coronary heart disease optimization system on Adaptive-Network-based Fuzzy Inference System and Linear Discriminant Analysis (ANFIS-LDA)," Journal Personal and Ubiquitous Computing, vol. 18, no. 6, pp. 1351-1362, 2014.

[3] S. Alomari, M. Shujauddin, and V. Emamian, "EKG Signals - De-noising and Features Extraction," Journal of Biomedical Engineering, vol. 6, no. 6, pp. 180-201, 2016.

[4] A. Surtono, T. S. Widodo, and M. Tjokronagoro, “Analisis Klasifikasi Sinyal EKG Berbasis Wavelet dan Jaringan Syaraf Tiruan,” Jurnal Nasional Teknik Elektro dan Teknologi Informasi (JNTETI), vol. 1, no. 3, pp. 60-66, 2012.

[5] R. Singh, R. Mehta, and N. Rajpal, "Efficient wavelet families for ECG classification using neural classifiers," in Journal Procedia Computer Science, 2018, vol. 132, pp. 11-21.

[6] B. W. Putra, R. F. Isnanto, and P. Sari, "Deteksi Arritmia pada Sinyal EKG dengan Deep Neural Network," in Seminar Nasional Sains dan Teknologi Terapan, 2020, vol. 3, no. 1, pp. 223-230.

[7] D. R. Oktaviani, W. Semarang, and I. Semarang, "Analisis Kelainan Jantung Menggunakan Dimensi Fraktal dan Transformasi Wavelet," Jurnal Ilmiah Matematika dan Terapan, vol. 17, no. 2, pp. 230-237, 2020.

[8] S. H. El-Khafif and M. A. El-Brawany, "Artificial Neural Network-Based Automated ECG Signal Classifier," Journal ISRN Biomedical Engineering, pp. 1-6, Jun. 2013.

[9] Darwan, S. Hartati, R. Wardoyo, and B. Y. Setianto, "The Feature Extraction to Determine the Wave 's Peaks in the Electrocardiogram Graphic Image,” International Journal of Image,graphics and signal processing, vol. 9, no. 6, pp. 1-13, 2017.

[10] J. Wang, P. Wang, and S. Wang, "Automated detection of atrial fibrillation in ECG signals based on wavelet packet transform and correlation function of random process," Biomedical Signal Processing and Control, vol. 55, pp. 1-9, Jan. 2020.

[11] N. Prashar, M. Sood, and S. Jain, "Design and implementation of a robust noise removal system in ECG signals using dual-tree complex wavelet transform,” Journal Biomedical Signal Processing and Control, vol. 63, pp. 1-12, Jan. 2021.

[12] S. Sahoo, B. Kanungo, S. Behera, and S. Sabut, "Multiresolution wavelet transform based feature extraction and ECG classification to detect cardiac abnormalities Multiresolution wavelet transform based feature extraction and ECG classification to detect cardiac abnormalities," Journal Measurement, vol. 108, pp. 55-66, 2017.

[13] K.-L. Du and M. N. S. Swamy, Neural Networks and Statistical Learning. London, Inggris: Springer, 2014.

[14] E. Alpaydin, Introduction to Machine Learning, Third. The MIT Press, 2014.

[15] A. Ehret, D. Hochstuhl, D. Gianola, and G. Thaller, "Application of neural networks with back-propagation to genome-enabled prediction of complex traits in Holstein-Friesian and German Fleckvieh cattle," pp. 1-9, 2015.

[16] M. F. Almas and B. D. Setiawan, "Implementasi Metode Backpropagation untuk Prediksi Harga Batu Bara,” vol. 2, no. 12, pp. 6502_ 
$6511,2018$.

[17] S. P. Siregar and A. Wanto, “Analysis Accuracy of Artificial Neural Network Using Backpropagation Algorithm In Predicting Process ( Forecasting )," vol. 1, no. 1, pp. 34-42, 2017.

[18] D. Huang and Z. Wu, "Forecasting outpatient visits using empirical mode decomposition coupled with back- propagation artificial neural networks optimized by particle swarm optimization," pp. 1-17, 2017.

[19] A. Haris, H. Slamet, B. H. Purnomo, and D. W. Soedibyo, "Model Jaringan Syaraf Tiruan untuk Prakiraan Harga Komponen Bahan Baku Pakan Unggas di PT XYZ Model of Artificial Neural Network for Price Forecasting of Poultry Feed Components at PT XYZ," vol. 9, no. 2, pp. 151-161, 2020.

[20] I. Prihandi, I. Ranggadara, S. Dwiasnati, and Y. S. Sari, "Implementation of Backpropagation Method for Identified Javanese Scripts Implementation of Backpropagation Method for Identified Javanese Scripts," 2020.

[21] Y. Aprizal, R. I. Zainal, U. B. Darma, J. S. Tiruan, and L. V. Quantization, "Perbandingan Metode Backpropagation and Learning Vector Quantization ( LVQ ) dalam Menggali Potensi Mahasiswa Baru di,” vol. 18, no. 2, pp. 294-301, 2019.

[22] J. Dong, Guozhu and Bailey, Contrast Data Mining : Concepts, Algorithms, and Applications. CRC Press, 2013.

[23] J. Han, Jiawei; Kamber, Micheline; Pei, Data Mining Concepts and Techniques, Third. Morgan Kaufmann Publishers, 2012. 
Matrik : Jurnal Manajemen, Teknik Informatika, dan Rekayasa Komputer,

Vol. 20, No. 2, Mei 2021: 355 366 